Baseline

\title{
Low incidence of plastic ingestion among three fish species significant for human consumption on the island of Newfoundland, Canada
}

\author{
Max Liboiron*, Jessica Melvin, Natalie Richárd, Jacquelyn Saturno, Justine Ammendolia, France Liboiron, \\ Louis Charron, Charles Mather \\ Department of Geography, Memorial University of Newfoundland, St. John's, NL A1B 3X9, Canada \\ Civic Laboratory for Environmental Action Research (CLEAR), Memorial University of Newfoundland, St. John's, Newfoundland A1B 3X9, Canada \\ School of Fisheries, Marine Institute of Memorial University of Newfoundland, St. John's, NL A1C 5R3, Canada \\ Program in Environmental Sciences, Memorial University of Newfoundland, St. John's, NL A1B 3X9, Canada \\ Department of Sociology, Memorial University of Newfoundland, St. John's, NL A1C 5S7, Canada \\ Department of Biology, Memorial University of Newfoundland, St. John's, Newfoundland A1B 3X9, Canada
}

\section{A R T I C L E I N F O}

\section{Keywords:}

Atlantic cod

Atlantic salmon

Capelin

Plastic

Ingestion

Marine debris

\begin{abstract}
A B S T R A C T
This study reports the first baselines of plastic ingestion for three fish species that are common commercial and sustenance food fish in Newfoundland. Species collections occurred between 2015 and 2016 for Atlantic cod (Gadus morhua), Atlantic salmon (Salmo salar), and capelin (Mallotus villosus). The frequency of occurrence (\%FO) of plastic ingestion for both Atlantic salmon $(n=69)$ and capelin $(n=350)$ was $0 \%$. Of the 1010 Atlantic cod individuals collected over two years, 17 individuals had ingested plastics, a \%FO of $1.68 \%$. This is the only multi-year investigation of plastic ingestion in Atlantic cod for the Northwest Atlantic, and the first baseline of plastic ingestion in Atlantic salmon and capelin on the island of Newfoundland. Considering the ecological, economic, and cultural importance of these fish species, this study is the beginning of a longitudinal study of plastic ingestion to detect any future changes in contamination levels.
\end{abstract}

Plastic ingestion by fish is a primary concern in Newfoundland, where both "recreational" (sustenance) and commercial fishing remains financially and culturally important to the people of the province. Within the context of the Newfoundland fishery, Atlantic cod yielded the second highest landed value for all captured groundfish species ( $\sim$ \$23 million), while capelin (Mallotus villosus) yielded the highest landed value of all pelagic species $(\sim \$ 13.5$ million) (Fisheries and Oceans Canada, 2017). The provincial recreational fisheries have one of the highest participation rates in Canada: 71,382 participants in 2010 according to Fisheries and Oceans Canada (2012). In a study of seafood preferences in rural communities in Western Newfoundland, both Atlantic cod and Atlantic salmon were the species most commonly consumed by respondents ( $81 \%$ and $42 \%$, respectively), while capelin was eaten less often, but remained a part of the diet of a majority of respondents (Lowitt, 2013).

This research provides a baseline for plastic ingestion in these three common Newfoundland food fish: Atlantic cod, Atlantic salmon, and capelin. This research: (1) builds upon and validates the existing preliminary finding of a \%FO of $2.45 \%$ in Atlantic cod collected in 2015 from the eastern coast of Newfoundland (Liboiron et al., 2016) to generate the first multi-year baseline for plastic ingestion in Atlantic cod of the Northwest Atlantic; and (2) establishes the first baseline of plastic ingestion in Atlantic salmon and capelin on the island of Newfoundland. Based on a review of the literature, no investigations have yet been made into the ingestion of plastics by Atlantic salmon or capelin. There are four preliminary reports of plastic ingestion in Atlantic cod that have surfaced in the Northeast Atlantic - specifically, in the North and Baltic seas (Bråte et al., 2016; Foekema et al., 2013; Lenz et al., 2015; Rummel et al., 2016). The production of a reliable baseline of plastic ingestion levels in these three species is the first step towards a reliable and useful long-term monitoring program for the region, especially given their cultural, ecological, and economic value.

This baseline study synthesises plastic ingestion data collected across the island of Newfoundland between 2015 and 2016, including inshore bays and harbours, as well as offshore regions of the Gulf of St. Lawrence, the Grand Banks and a collection site north of Labrador (Davis Strait) (Fig. 1). "Offshore" was considered as any region $>30 \mathrm{~km}$ from the shoreline whereas "inshore" was an area $<30 \mathrm{~km}$ from the shoreline $(30 \mathrm{~km}$ was selected based on the distance indicated by fishers whose activities are governed by these categories). Fish were collected from scientific (Atlantic cod, Atlantic salmon), commercial (capelin) and recreational sources (Atlantic cod). Gastrointestinal (GI) tracts were removed in the field for both Atlantic cod and Atlantic salmon, while

\footnotetext{
* Corresponding author.

Email address: mliboiron@mun.ca (M. Liboiron)
} 


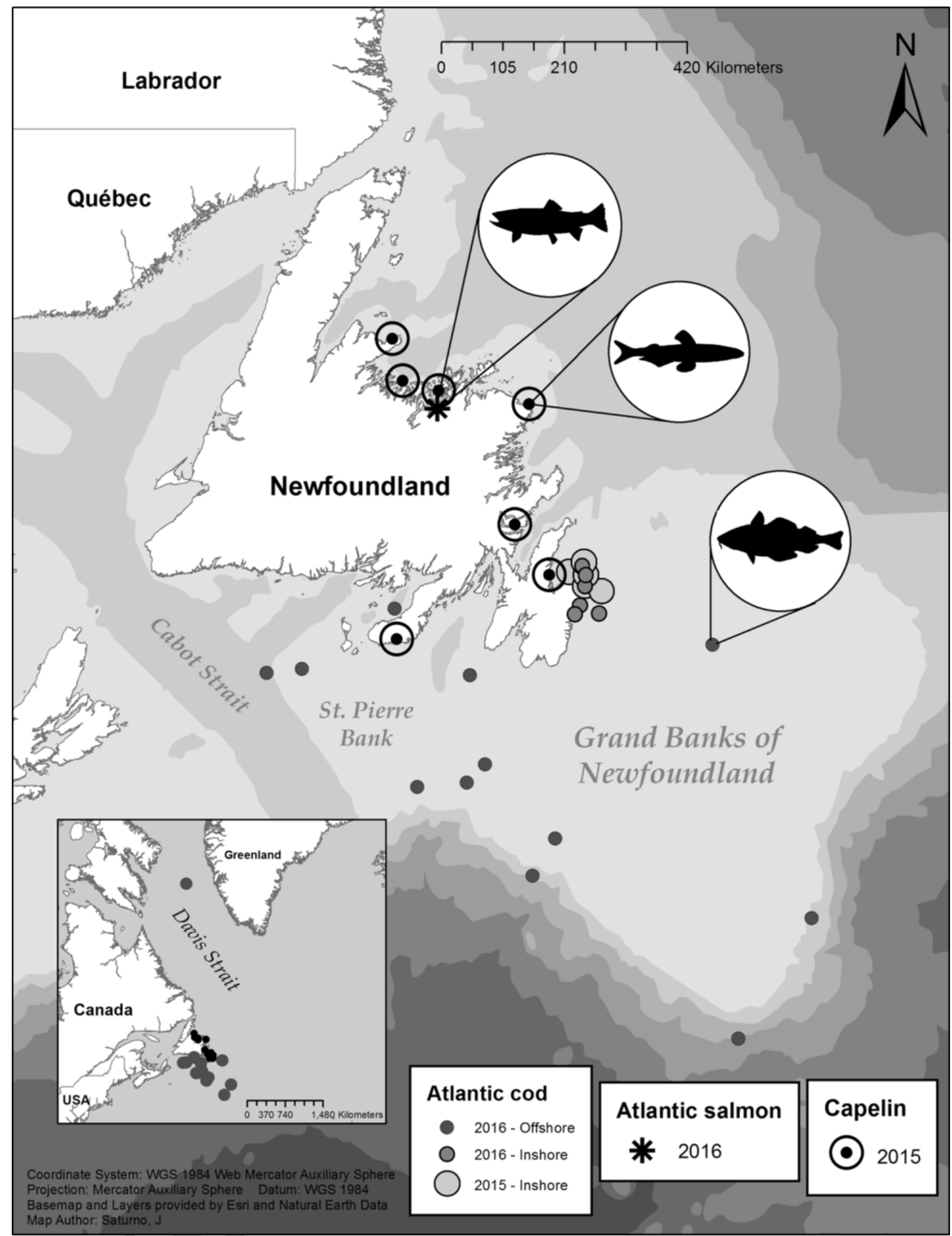

Fig. 1. Collection locations for the Atlantic cod, Atlantic salmon, and capelin from 2015 to 16. (Map: J. Saturno)

capelin were collected whole. Collection details are outlined in S3. For further details regarding collection protocols refer to S1.

We used standardized plastic ingestion research protocols using nested sieves (\#4, \#18) identical to Liboiron et al. (2016) to compare previous studies in the province. The minimum size of detection was $1 \mathrm{~mm}$. To control for microplastic contamination in the laboratory, we used a cotton laboratory coat, wore gloves, and tied hair back, rinsed all tools under tap water before and after each sample, and used daily control dishes to capture particles settling from the air using double sided tape. In the event that a fibre was found in a GI tract, it was compared to fibres present in the control dish. Plastic contaminants were occasionally found on the external surface of the stomach and/or intestines for Atlantic cod $(n=15)$. These particles were identified as wood splinters and paint chips that visually matched the inventory of field tools and were assumed to have been transferred during sample collection.

Visual identification of microplastics through use of a microscope was used, as it has been confirmed as a reliable method for identifying particles $>1 \mathrm{~mm}$ in size (Song et al., 2015). We recorded and quantified the presence or absence of plastic(s) for each individual fish and calculated the population average (\%FO). The colour, weight, length, type and weathering details of plastics were recorded. Plastics were weighed on a scale sensitive to $0.0001 \mathrm{~g}$ and 
length measurements were taken from the longest axis of the plastic using digital calipers. Plastics smaller than $5 \mathrm{~mm}$ in maximum length were classified as microplastics, while plastics from 5 to $20 \mathrm{~mm}$ were classified as mesoplastics (and those over $20 \mathrm{~mm}$ as macroplastics, though such plastics are rare in ingestion studies). These methods follow methods established in Avery-Gomm et al. (2016) and Liboiron et al. (2016).

Plastic characteristics (type, colour, length, mass, weathering and polymer) were quantified as a percentage of all particles for which the characteristic in question could be determined. Plastic types were categorized as either: industrial resin pellets, sheet/film (i.e. plastic bags), threads (i.e. fishing line, rope), foamed plastics (i.e. polystyrene packaging), fragments (i.e. hard plastics from a wide array of products), fibres (i.e. from clothing), microbeads (i.e. from personal care products) or other. In order to evaluate the state of plastic erosion each particle was assessed for: discolouration, fraying, fracturing, pits and grooves, and adhered particles (Corcoran et al., 2009), as well as burning or melting (Avery-Gomm et al., 2016). Raman micro-spectrometry (Reinshaw InVia with $830 \mathrm{~nm}$ excitation) was conducted only on particles obtained from Atlantic cod collected in 2016, Atlantic salmon and capelin. This analysis was not available for the Atlantic cod collected in 2015. However, no plastics from 2015 were visually ambiguous. Particles that could not be weighed (because they were lost prior to weighing or were too small to register) were assigned a mass of $0 \mathrm{~g}$ for calculations involving the entire sample population, and left out of calculations for the sub-population of individuals with ingested plastics.

A total of 1429 individuals from 3 different species were collected and only Atlantic cod were found to have ingested plastics. A total of 17 individuals contained plastic, resulting in a \%FO of $1.68 \%(n=1010$, $\mathrm{SD}=0.130$ ) for the species (Table 1). All but two of the 17 fish with ingested plastic $(n=15)$ had ingested only one plastic, while two of the fish collected in 2015 had ingested two plastics each. The mean number of plastics ingested per individual for the entire sample was 0.019 particles/individual $(n=1010, \mathrm{SD}=0.150)$. Of the sub-population of Atlantic cod that had ingested plastic, the mean number of plastic particles ingested per individual is 1.12 particles/individual $(n=17$, $\mathrm{SD}=0.330$ )

The $\%$ FO of the 2015 citizen science survey collection did not significantly differ from individuals collected in $2016(p=0.730$, $\mathrm{df}=1$, $n=552$ ). Therefore, the subsequent analyses of these datasets were combined (with the exception of the analysis of year as an independent variable) and are hereafter referred to as the recreational survey. A total of 12 of 552 fish from the recreational survey of Atlantic cod had ingested plastic, yielding a $\% \mathrm{FO}$ of $2.17 \%(n=552, \mathrm{SD}=0.150)$. The scientific survey of Atlantic cod found plastic in 5 out of 458 fish collected for a $\% \mathrm{FO}$ of $1.09 \%(n=458, \mathrm{SD}=0.100)$. The comparison of results between fish from recreational and scientific collections yielded no significant difference in plastic ingestion ( $p=0.170, \mathrm{df}=1, n=1010)$, and are therefore presented together as a total \%FO (1.68\%) for the species.

Both food presence and sex were each significantly related to \% $\mathrm{FO}$ $(p<0.05)$, while there was no evidence of a significant relationship between $\% \mathrm{FO}$ and temporal or regional variables $(p>0.05)$. Sex was identified for 10 out of the 17 individuals with ingested plastic. Of these 10 individuals, 9 were females. Females were determined to have a significantly higher \%FO than males $(p<0.05)$. All 17 individual cod that had ingested plastic had also ingested other food items. Although most individuals had consumed food (71\%), the presence of food in the stomach was a significant factor in predicting the

Table 1

Summary of the results for plastic ingestion rates (\%FO) among three fish species collected from Newfoundland.

\begin{tabular}{llll}
\hline Species & $\begin{array}{l}\text { Collection } \\
\text { year(s) }\end{array}$ & $\begin{array}{l}\text { Sample } \\
\text { size }(n)\end{array}$ & $\begin{array}{l}\text { Mean plastic ingestion } \\
\text { rate (\%FO } \pm \text { SD) }\end{array}$ \\
\hline $\begin{array}{c}\text { Atlantic cod (Gadus } \\
\text { morhua) }\end{array}$ & $2015-2016$ & 1010 & $1.68 \pm 0.129$ \\
$\begin{array}{c}\text { Atlantic salmon } \\
\text { (Salmo salar) } \\
\begin{array}{c}\text { Capelin (Mallotus } \\
\text { villosus) }\end{array}\end{array}$ & 2016 & 69 & 0 \\
\hline
\end{tabular}

presence of ingested plastic $(p<0.01)$, whereby individuals that ingested prey were more likely to contain plastic. Relative to Atlantic cod, the sample populations of both Atlantic salmon and capelin investigated here (and found to be free of ingested plastic) had considerably low proportions of fed individuals (20\% of salmon and $23 \%$ of capelin). See Table S6 for details.

Green threads were recovered in Atlantic cod from both sampling years (refer to S5). Green is the colour that is most attributable to some of the fishing industry's most common fishing gear: polyethylene, polypropylene, and polysteel ropes and threads (Knowlton et al., 2016; Murray and Cowie, 2011). The green thread recovered from an Atlantic cod individual in 2016 was confirmed by Raman micro-spectrometry to be polyethylene and green was the second most common colour of particles recovered from cod in this research.

A breakdown of type, size and colour of recovered plastic particles is shown in Fig. 2. The particle lengths ranged from $1.6 \mathrm{~mm}$ to $12.1 \mathrm{~mm}$, with a mean length of $5.6 \mathrm{~mm}(n=16, \mathrm{SD}=3.140)$. Measurements could not be recorded for three plastic particles that were visually identifiable as microplastics, either because they were lost prior to analysis $(n=2)$, or were too small to register on the scale $(n=1)$. The masses of the plastic for which weight could

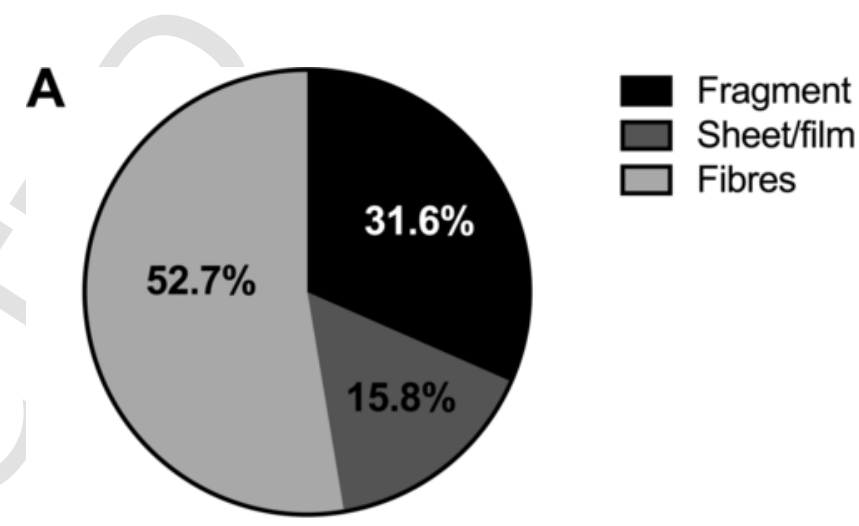

B
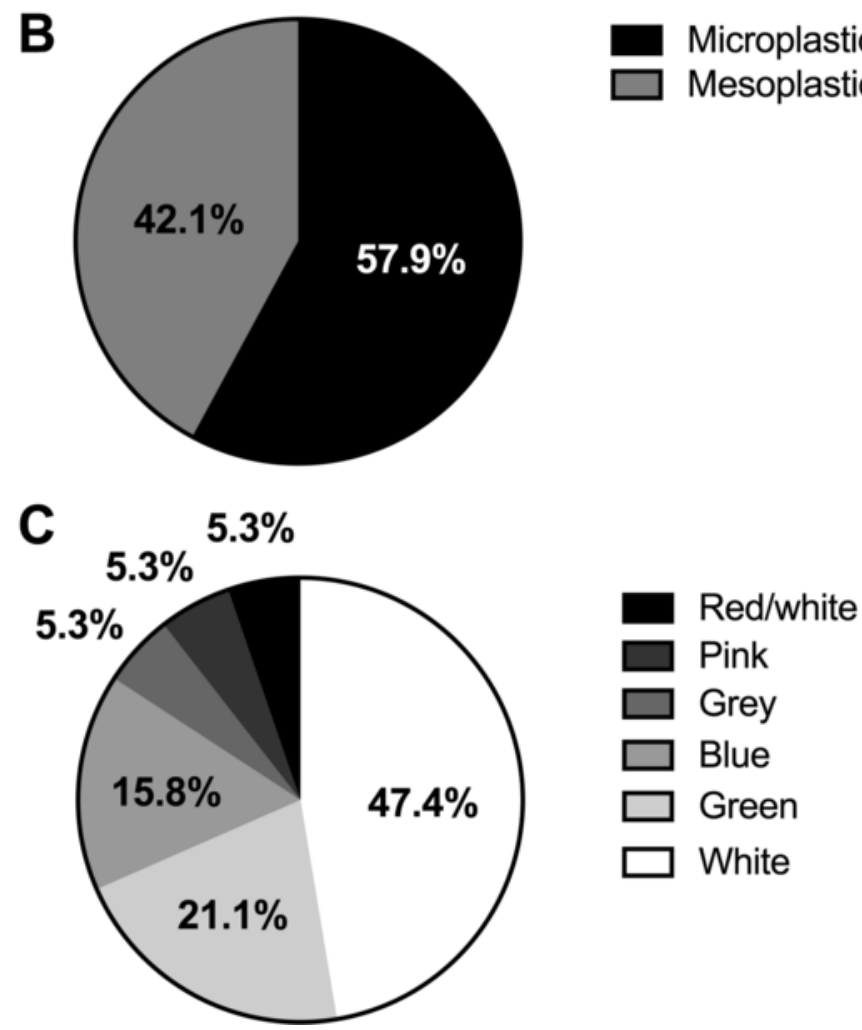

Fig. 2. The characteristics for plastic particles recovered from Atlantic cod captured in Newfoundland from 2015 to 2016 for the following: (A) plastic type, (B) plastic size, as microplastics $(<5 \mathrm{~mm})$ or mesoplastics $(5-20 \mathrm{~mm})$ and, $(C)$ plastic colour. 
be determined ( $n=14)$, ranged from $0.0001 \mathrm{~g}$ to $0.6970 \mathrm{~g}$, with a mean mass of $0.0510 \mathrm{~g}(n=14, \mathrm{SD}=0.190$; Table 4$)$. The masses were not recorded for 5 particles, either because they were lost prior to weighing $(n=3)$ or were too lightweight to register $(n=2)$. The high standard deviation is attributed to the outlier mass of one of the particles (a piece of rope); when this particle was removed, the mean mass of the remaining 13 particles, was $0.0015 \mathrm{~g}(n=13, \mathrm{SD}=0.002)$. The mean weight of plastic for the entire sample population of Atlantic cod (including individuals that had not ingested plastic) is $0.0007 \mathrm{~g}$ per individual $(n=1010, \mathrm{SD}=0.022)$. Of the sub-population of Atlantic cod that had ingested plastic(s), the mean weight of plastic is $0.0420 \mathrm{~g}$ per individual $(n=17, \mathrm{SD}=0.170)$.

The following plastic polymers were identified for particles recovered from Atlantic cod using Raman micro-spectrometry: polyethylene (PE), polyvinylchloride (PVC), polyethylene terephthalate (PET), acrylonitrile butadiene styrene (ABS), and polycarbonate (PC). For more details on spectrometry results, see S2. All polymers identified (either conclusively or suspected) in Raman spectrometry $(n=8)$ were of a higher density than seawater, with the exception of polyethylene. Polyethylene was the most commonly identified polymer and is ubiquitously used in the production of fishing gear.

Nine of the particles (47\%) had no discernable weathering or erosion patterns, while the rest of the particles $(53 \%, n=10)$ had various forms of weathering, including pits and grooves $(n=5)$, fracturing $(n=4)$, adhered particles $(n=2)$, fraying $(n=4)$, discolouration $(n=2)$, melting $(n=1)$ and irregular surface textures $(n=2)$. There was a higher proportion of particles recovered from offshore cod that displayed considerable weathering $(29 \%, n=2)$ relative to particles from inshore fish $(17 \%, n=2)$, but the frequency of occurrence of the weathered particles did not vary between offshore and inshore fish $(p=0.510, \mathrm{df}=1$, $n=19$ ). Refer to S4 for full details of plastic forensics.

It is worth noting that three plastic particles were microfibres and the possibility of contamination needs to be addressed. Two particles were enmeshed in a conglomerate of partially digested material (refer to S5), eliminating the possibility of contamination via atmospheric deposition, as is common with microfibres (Fries et al., 2013; Hidalgo-Ruz et al., 2012; Nuelle et al., 2014; Woodall et al., 2015). Although the third microfibre was small enough to be atmospherically deposited, it did not match any fibres present in the control dishes and instead was embedded in a bundle of red algae. As none of these fibres resembled any from the control dishes, and did not appear to be atmospherically deposited because of their entanglement in organic sample material, these microfibres are not considered to be a product of contamination.

The ingestion of plastics by Atlantic cod has been examined over a wide geographic range beyond this study, with a particular focus on the Northeast Atlantic. The reported results from this region have been highly variable. Rummel et al. (2016) and Bråte et al. (2016) report $\%$ FO values of $\leq 3 \%$ for the species in the North, Baltic and Norwegian seas. By contrast, earlier studies reported higher $\% \mathrm{FO}$ values for Atlantic cod in the same region ranging from $13 \%$ (Foekema et al., 2013) to $39 \%$ (Lenz et al., 2015) in the North Sea, and 21\% in the Baltic Sea (Lenz et al., 2015). Low plastic ingestion levels reported for Atlantic $\operatorname{cod}(<3 \% \mathrm{FO})$ that are complementary to the results reported here stem from studies that similarly rely on the visual identification of plastics (Bråte et al., 2016; Rummel et al., 2016). Meanwhile, reports of relatively high plastic ingestion levels in Atlantic cod ( $>10 \%$ FO) have stemmed from studies that employ acid digestion of digestive contents and can identify plastics $<1 \mathrm{~mm}$ in size (Foekema et al., 2013; Lenz et al., 2015), thus increasing the size range of identifiable plastics and the resultant $\% \mathrm{FO}$ for the sample population. Acid digestion protocols are not suitable to the long-term monitoring developed by CLEAR for its accessibility to citizen scientists and so are not used in this study (see Liboiron et al., 2016).

Sample sizes for Atlantic cod plastic ingestion research range from 7 (Rummel et al., 2016) to 302 (Bråte et al., 2016) individuals. The ideal minimum sample size for plastic ingestion studies is species specific and depends on the \%FO for that species (larger sample size required for species exhibiting a lower \%FO), as well as any interannual variability in that average. There are too few records of plastic ingestion in Atlantic cod across various sample sizes to conduct size the variance in reported \%FO decreases, as described by van Franeker and Meijboom (2002). Moreover, literature reviews of plastic ingestion studies in fish have found that many sample sizes are too small for reliable species-specific baselines (Liboiron et al., 2018).

This study's sample sizes ( $n=69$ for salmon, $n=350$ for capelin, and $n=1110$ for Atlantic cod) ensure the baseline for these species in the region are valid, and can be used to assess changes over time in future studies.

\section{Acknowledgements}

We acknowledge that this research was conducted on the unceded, unsurrendered ancestral Lands of the Mi'kmaq and Beothuk peoples. We would also like to acknowledge the Inuit of Nunatsiavut and NunatuKavut and the Innu of Nitassinan, and their ancestors, as the original peoples of Labrador.

This project was funded by the following grants, awarded to PI Max Liboiron: SSHRC Insight Development Grant (\#430-2015-00413), SSHRC Insight Grant (\#435-2017-0567), MEOPAR/ISI early career grant ("Monitoring Marine Plastics in Canada's North").We would like to acknowledge Fisheries and Oceans Canada and the Fisheries and Marine Institute of Memorial University for providing the offshore survey samples. We would like to extend our appreciation to the Merschod Lab for help with Raman Spectrometry. We would also like to thank all of the commercial and recreational fishermen who invited us to participate in their filleting process for the donation of samples. For the salmon donations we would like to thank: Dr. Martha Roberts (DFO), Kristin BØe, Jacqueline Chapman, Robert Lennox and the Cooke Lab. For cod and capelin collections we extend our appreciation to: Centre for Fisheries Ecosystems Research, the crew of the $R V$ Celtic Explorer, Susan Fudge, Laura Wheeland and the Government of Newfoundland and LabradorFisheries and Land Resources.

\section{Appendix A. Supplementary data}

Supplementary data to this article can be found online at https:// doi.org/10.1016/j.marpolbul.2019.02.057.

\section{References}

Avery-Gomm, S., Valliant, M., Schacter, C.R., Robbins, K.F., Liboiron, M., Daoust, P.-Y., Rios, L.M., Jones, I.L., 2016. A study of wrecked Dovekies (Alle alle) in the western North Atlantic highlights the importance of using standardized methods to quantify plastic ingestion. Mar. Pollut. Bull. 113, 75-80. https://doi.org/10.1016/j.marpolbul. 2016.08.062

Bråte, I.L.N., Eidsvoll, D.P., Steindal, C.C., Thomas, K.V., 2016. Plastic ingestion by Atlantic cod (Gadus morhua) from the Norwegian coast. Mar. Pollut. Bull. 112, 105-110. https://doi.org/10.1016/j.marpolbul.2016.08.034.

Fisheries and Oceans Canada, 2012. Survey of recreational fishing in Canada, 2010 (No. DFO/2012-1804). Government of Canada, Ottawa.

Fisheries and Oceans Canada, 2017. Landings and Landed Value by Species: Newfoundland and Labrador Region. Department of Fisheries and Oceans Canada, Retrieved from http://www.nfl.dfo-mpo.gc.ca/publications/reports_rapports/Land_All_Vessels Debarquer_Tous_Les_Navires_2016 eng.htm.

Foekema, E.M., De Gruijter, C., Mergia, M.T., van Franeker, J.A., Murk, A.J., Koelmans, A.A., 2013. Plastic in North Sea fish. Environ. Sci. Technol. 47, 8818-8824. https:// doi.org/10.1021/es400931b.

Knowlton, A.R., Robbins, J., Landry, S., McKenna, H.A., Kraus, S.D., Werner, T.B., 2016. Effects of fishing rope strength on the severity of large whale entanglements. Conserv. Biol. 30, 318-328. https://doi.org/10.1111/cobi.12590.

Lenz, R., Enders, K., Beer, S., Sørensen, T.K., Stedmon, C.A., 2015. Analysis of microplastic in the stomachs of herring and cod from the North Sea and Baltic Sea (Technical Report). DTU Aqua, National Institute of Aquatic Resources, Denmark.

Liboiron, M., Liboiron, F., Wells, E., Richard, N., Zahara, A., Mather, C., Bradshaw, H., Murichi, J., 2016. Low plastic ingestion rate in Atlantic cod (Gadus morhua) from Newfoundland destined for human consumption collected through citizen science methods. Mar. Pollut. Bull. 113, 428-437.

Liboiron, F., Ammendolia, J., Saturno, J., Melvin, J., Zahara, A., Richárd, N., Liboiron, M., 2018. A zero percent plastic ingestion rate by silver hake (Merluccius bilinearis) from the south coast of Newfoundland, Canada. Mar. Pollut. Bull. 131, 267-275. https:// doi.org/10.1016/j.marpolbul.2018.04.007.

Lowitt, K., 2013. Examining fisheries contributions to community food security: findings from a household seafood consumption survey on the west coast of Newfoundland. J. Hunger Environ. Nutr. 8, 221-241. https://doi.org/10.1080/19320248.2013.786668. Murray, F., Cowie, P.R., 2011. Plastic contamination in the decapod crustacean Nephrops 
Rummel, C.D., Löder, M.G.J., Fricke, N.F., Lang, T., Griebeler, E.-M., Janke, M., Gerdts, G., 2016. Plastic ingestion by pelagic and demersal fish from the North Sea and Baltic Sea. Mar. Pollut. Bull. 102, 134-141. https://doi.org/10.1016/j.marpolbul.2015.11. 043. van Franeker, J.A., Meijboom, A., 2002. LITTER NSV, Marine Litter Monitoring by Northern Fulmars; A Pilot Study (Alterra-Rapport 401). Alterra, Green World Research, Wageningen. 